\title{
ADEQUAÇÃO SOCIOAMBIENTAL DE ÁREA DEGRADADA PELO DESCARTE INADEQUADO DE RESÍDUOS SÓLIDOS
}

\author{
${ }^{1}$ Yuri Lorran Braga Cunha - yuri.lorran @ hotmail.com \\ ${ }^{1}$ Rosalina Medeiros de Souza - rozalinna_medeiro@yahoo.com.br \\ ${ }^{1}$ Aleff Maurício de Sousa Antunes - aleffmsantunes@ hotmail.com \\ ${ }^{1}$ Raquel Dias Rodrigues - raqueldiascmd@yahoo.com.br \\ ${ }^{1}$ Leilane Cristina Duarte Ferreira - leilane.ambiental@ gmail.com \\ ${ }^{1}$ Dayane de Jesus Pereira - day_2408@yahoo.com.br \\ ${ }^{1}$ Thaís Gabrielly Michel Costa - thaisgmichel@ gmail.com \\ ${ }^{1}$ Thaislane Sabrina de Souza Oliveira - thaisz2007@ hotmail.com \\ ${ }^{1}$ Athâmis Hana Gonçalves de Carvalho - athamishanna@gmail.com \\ ${ }^{1}$ Lílian Michelle Matoso Marçal de Faria - lilianmmarcal@gmail.com \\ ${ }^{1}$ Christiane Lorrayne Michel de Carvalho - chrislorraine@ hotmail.com \\ ${ }^{1}$ Claudineia Lizieri - c.lizieri@ gmail.com \\ ${ }^{1}$ Instituto de Engenharia e Tecnologia - IET, Centro Universitário de Belo \\ Horizonte - UniBH
}




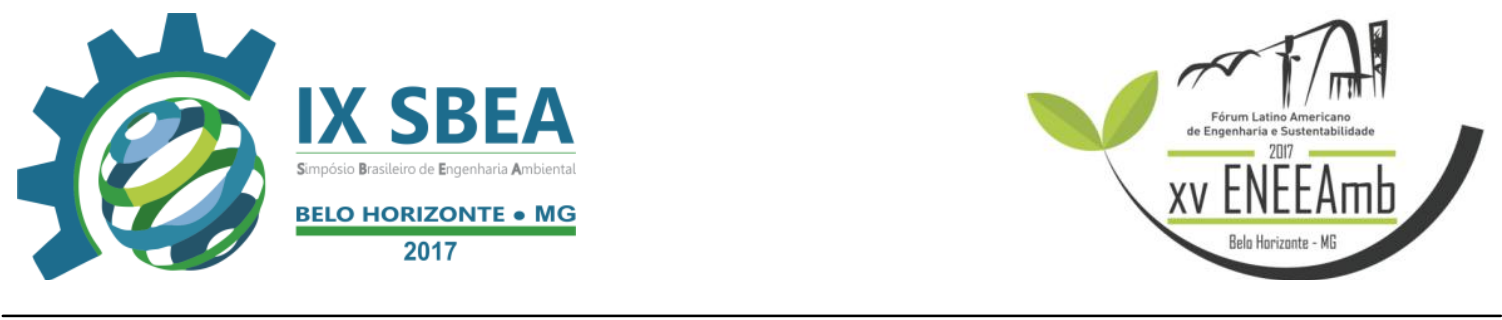

\section{RESUMO}

Considerando o crescimento populacional, o aumento da produção de resíduos e a necessidade de procedimentos para seu descarte e disposição final, este trabalho estuda um aterro sanitário, o qual, atualmente, encontra-se com disposição incorreta de resíduos sólidos, como um modelo para discussão e medidas de gestão socioambientais. Através de observações na área de estudo, entrevistas à população do entorno e levantamentos bibliográficos, foram desenvolvidas propostas de adequação visando o cumprimento do determinado na legislação e pensando nos princípios da sustentabilidade socioambiental, envolvendo a preocupação com o meio ambiente e com a população afetada.

Palavras-chave: Adequação socioambiental. Área degradada. Aterro sanitário. Descarte irregular. Lixão. Resíduos sólidos.

\section{INTRODUÇÃO/OBJETIVO}

O crescimento populacional, somado ao desenvolvimento de hábitos de consumo excessivo das pessoas, teve como resultado o aumento gradativo do volume de resíduos sólidos (RS) (BRAGA et al., 2005; RESENDE et al., 2015). Em 2014, a população brasileira gerou 215 mil toneladas de RS diários, de acordo com a Associação Brasileira de Empresas de Limpeza Pública e Resíduos Especiais ABRELPE (2014) sendo estes, em muitos casos, descartados em áreas sem tratamento prévio e fiscalização adequada (BRAGA et al., 2005; RESENDE et al., 2015).

A Política Nacional de Resíduos Sólidos (PNRS) proíbe o lançamento in natura a céu aberto e regulamenta formas adequadas de destinação e disposição final, incluindo-se o aterro sanitário. Segundo a NBR 8.419/1992 e a NBR 15.849/2010 da Associação Brasileira de Normas Técnicas (ABNT) aterros sanitários minimizam os danos à saúde pública e ao meio ambiente. Apesar do número razoável de normativas existentes atualmente, há ainda muito descumprimento das mesmas, principalmente em municípios desprovidos de políticas públicas fortalecidas voltadas para estas questões, resultando na construção de lixões e/ou aterros sem cuidados específicos que devem ser seguidos no seu planejamento. 
No trabalho de ABRELPE (2014) foram identificados 1.559 munícipios brasileiros, que adotam o lixão como destinação final dos RS, enquanto no ano de 2013 havia 1.569 municípios com lixão no país, demonstrando uma redução de apenas $0,6 \%$ desta prática entre os dois anos de estudo. Esses dados evidenciam um avanço muito lento na evolução da adequação de despejo dos RS e reforçam a necessidade de promover políticas públicas associadas à erradicação deste tipo de atividade no país, as quais têm se tornado um dos maiores problemas relacionados ao saneamento básico. Adicionalmente, este tipo de atividade, expõe a população local a interferências que refletem negativamente no modo de vida dessas pessoas e impede qualquer tipo de atividade produtiva, tanto no local de disposição dos resíduos quanto em seu entorno (CAVALCANTE; FRANCO, 2007; MUCELIN; BELLINI, 2008; GOUVEIA, 2012; RESENDE et al., 2015).

Os principais fatores que contribuem para degradação de áreas por RS, são produção de chorume e a liberação de gases tóxicos (BRAGA et al., 2002). Estes produtos podem acarretar diversos impactos, poluindo o ar, água e solo, além da depreciação do local e seus arredores devido ao odor e aos aspectos visuais negativos (ALBERTE et al., 2005; MUCELIN; BELLINI, 2008). A implantação de projetos e planos que visam a recuperação destas áreas, observando o grau de degradação, além do monitoramento dos impactos detectados e avaliação da evolução dos problemas são de extrema importância (BELI et al., 2005; RESENDE et al., 2006).

Diante deste cenário, o presente trabalho realizou um diagnóstico socioambiental da Central de Tratamento de Resíduos Sólidos do município de Betim, Minas Gerais (MG) e traz sugestões de medidas para adequação da área visando estabelecer a saúde ambiental e social da região.

\section{METODOLOGIA}

\subsection{Descrição da Área de Estudo}

A área da Central de Tratamento de Resíduos Sólidos consiste em um aterro sanitário, o qual teve seu funcionamento encerrado em 2011, contudo, ainda com uma inadequada disposição de resíduos. Localizada nas imediações do bairro Citrolândia, município de Betim, MG, a área tem 34 hectares, em coordenadas geográficas Latitude 


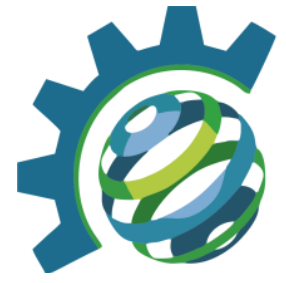

$20^{\circ} 01^{\prime} 01.82$ 'S e Longitude $44^{\circ} 14^{\prime} 15.16^{\prime \prime} \mathrm{W}$. Sua capacidade volumétrica de armazenamento é calculada em $695.853 \mathrm{~m}^{3}$.

Segundo o IBGE (2016), o município de Betim ocupa uma área de 343,736 km², está situado na Região Metropolitana de Belo Horizonte. Em 2010, Betim possuía uma população de 378.089 habitantes, com uma projeção estimada de 415.307 habitantes para o ano de 2015, e sua densidade demográfica é de $1.102,80$ habitantes por $\mathrm{km}^{2}$ (IBGE, 2016). A localização da área de estudo em relação ao município de Betim é mostrada na figura 1. O mapa foi elaborado no software ArcGIS versão 10.4, utilizando dados do IBGE (2016).

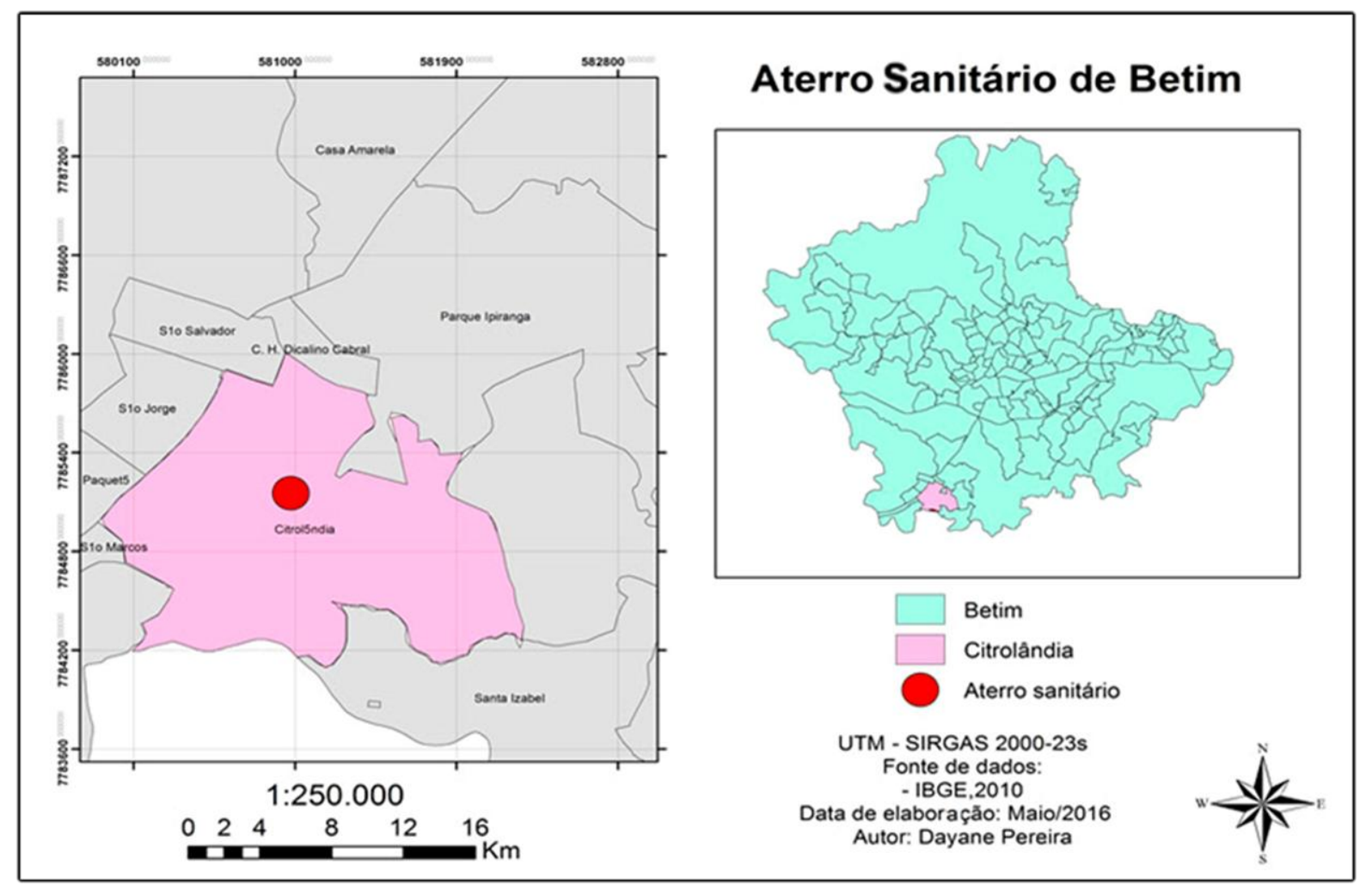

Figura 1: Localização aproximada da área de estudo.

Fonte: IBGE, 2016 (adaptado).

\subsection{Revisão Bibliográfica}

A revisão bibliográfica do presente estudo foi realizada visando a compreensão da problemática exposta e contextualização do estado da arte. As informações levantadas tiveram como base as legislações aplicadas à gestão de resíduos sólidos e 
bibliografias relacionadas ao saneamento básico, à recuperação de áreas degradadas, à gestão de resíduos sólidos, à engenharia ambiental e sanitária e à gestão ambiental. Além disso, foram consultadas informações em manuais, cartilhas e artigos científicos.

\subsection{Levantamento de Informações in loco}

A primeira visita, realizada no dia 09/04/2016, objetivou a caracterização do ambiente, a qual foi realizada através de registros fotográficos e observações visuais. A segunda visita, realizada em 22/05/2016, visou o levantamento de informações com vinte (20) moradores do entorno do local de estudo, sendo uma pesquisa amostral em que as informações foram qualificadas, quantificadas e posteriormente, plotadas em gráficos e tabelas através do software Microsoft Office Excel 2010. As perguntas questionadas foram as seguintes: 1) Quais são os principais motivos para solicitação do fechamento do aterro sanitário, em 2011?; 2) Após o fechamento do aterro, o local permaneceu por algum período sem receber resíduos?; 3) Atualmente, você se sente afetado em relação ao funcionamento do aterro?; 4) Existe mobilização da população para pedir a interrupção do lançamento de resíduos no local?; 5) Atualmente, quais são os impactos que acometem a população do entorno?

\section{RESULTADOS E DISCUSSÃO}

Foi constatada a disposição irregular de RSU, resíduos da construção civil (RCC) e resíduos orgânicos, acima do maciço de resíduos do aterro sanitário. Verificouse degradação do solo, o qual apresenta completamente exposto a possíveis erosões e passivo de contaminação por metal pesado e outros contaminantes (orgânicos ou inorgânicos) devido o lixo ser proveniente de diversas fontes.

Outro fator identificado foi o potencial para a proliferação de organismos dissipadores de doenças, onde foi constatado vários tipos de recipientes acumuladores de água, os quais podem abrigar larvas e insetos causadores de doenças infecciosas, tal como dengue, disenteria, cólera, dentre outras. Soma-se a isso, o risco de doenças respiratórias, que podem ser desencadeadas, pela presença de material particulado no ar visualizado no local e entorno. A área não conta com proteção externa, sendo atualmente de livre acesso a qualquer cidadão. Foram constatados vazamento e falta de 
monitoramento de chorume, inatividade de queimadores de gás metano e das lagoas de estabilização.

A partir do questionário aplicado, foi possível entender a percepção da população em relação ao empreendimento e os reais impactos sentidos pelos cidadãos. Os resultados obtidos através da primeira pergunta visaram à caracterização qualitativa dos motivos de solicitação de fechamento do aterro sanitário em 2011. As respostas obtidas são sumarizadas na Tabela 1:

Tabela 1

Fatores que levaram a população a solicitar o fechamento do aterro sanitário.

\begin{tabular}{|l|c|}
\hline \multicolumn{1}{|c|}{ Motivo apontado } & Quantidade de moradores citando o motivo \\
\hline Mau cheiro e material particulado & 10 \\
\hline Presença de animais e doenças & 5 \\
\hline Poluição sonora & 5 \\
\hline Tremores e danos físicos às residências & 5 \\
\hline Esgotamento da vida útil do aterro & 3 \\
\hline Morte de operário em outro aterro & 1 \\
\hline Não souberam/não quiseram responder & 3 \\
\hline
\end{tabular}

A segunda pergunta objetivou compreender se, após o fechamento do empreendimento, este ficou sem receber resíduos. As respostas obtidas são descritas na Figura 6. 

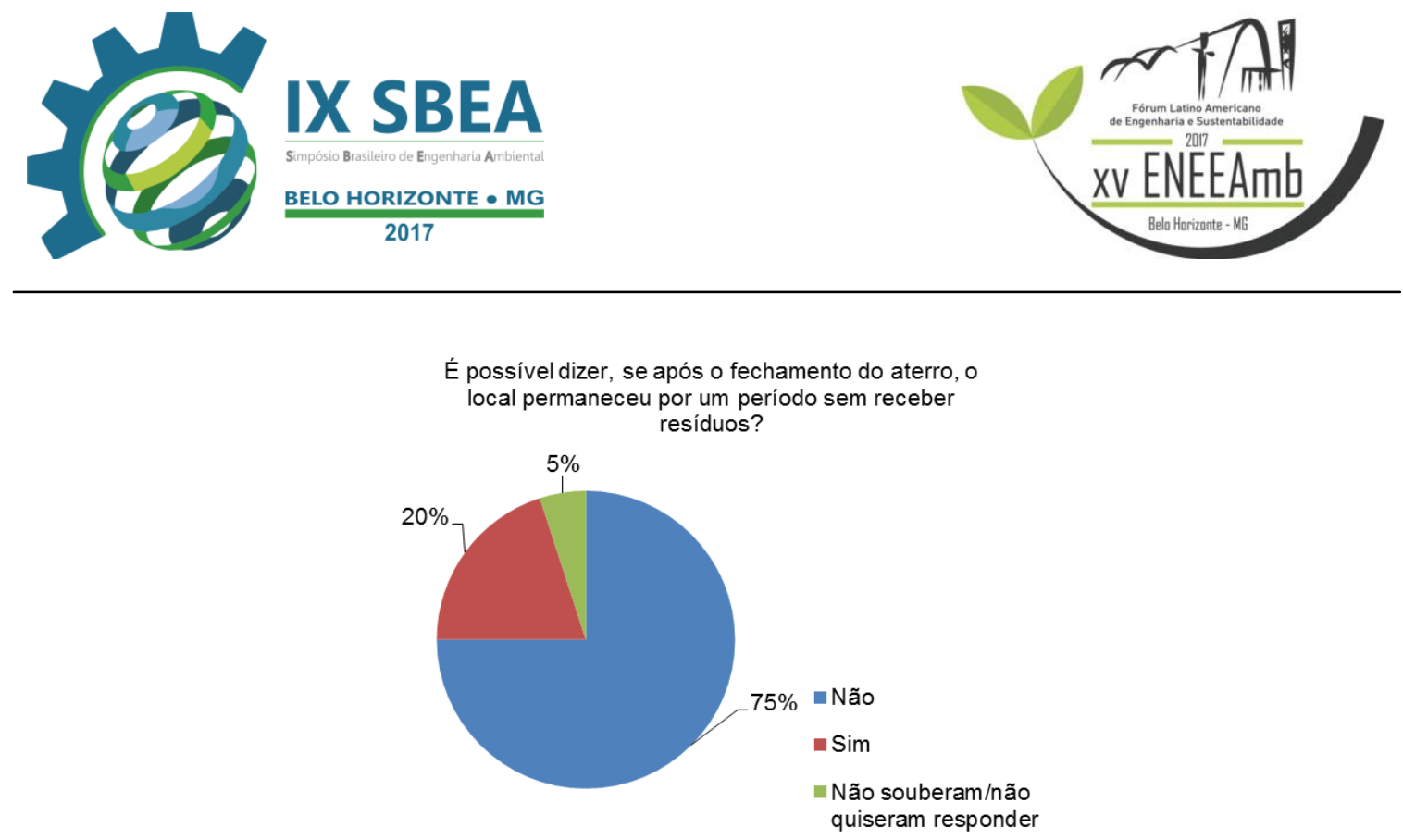

Figura 6: Percentual de respostas referentes à Questão 2.

O terceiro questionamento foi direcionado a saber como as pessoas, atualmente, se sentem em relação ao funcionamento do aterro sanitário, considerando o atual descarte irregular de resíduos. As respostas obtidas são apresentadas na Figura 7.

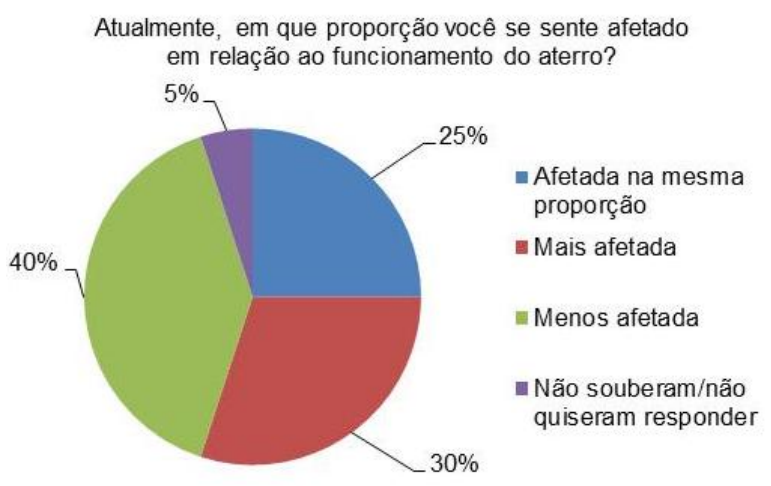

Figura 7: Percentual de respostas referentes à Questão 3.

Em seguida foi perguntado aos moradores, se havia uma percepção com relação à mobilização da população visando à interrupção permanente do descarte de resíduos no local de estudo. O resultado obtido está descrito na Figura 8. 

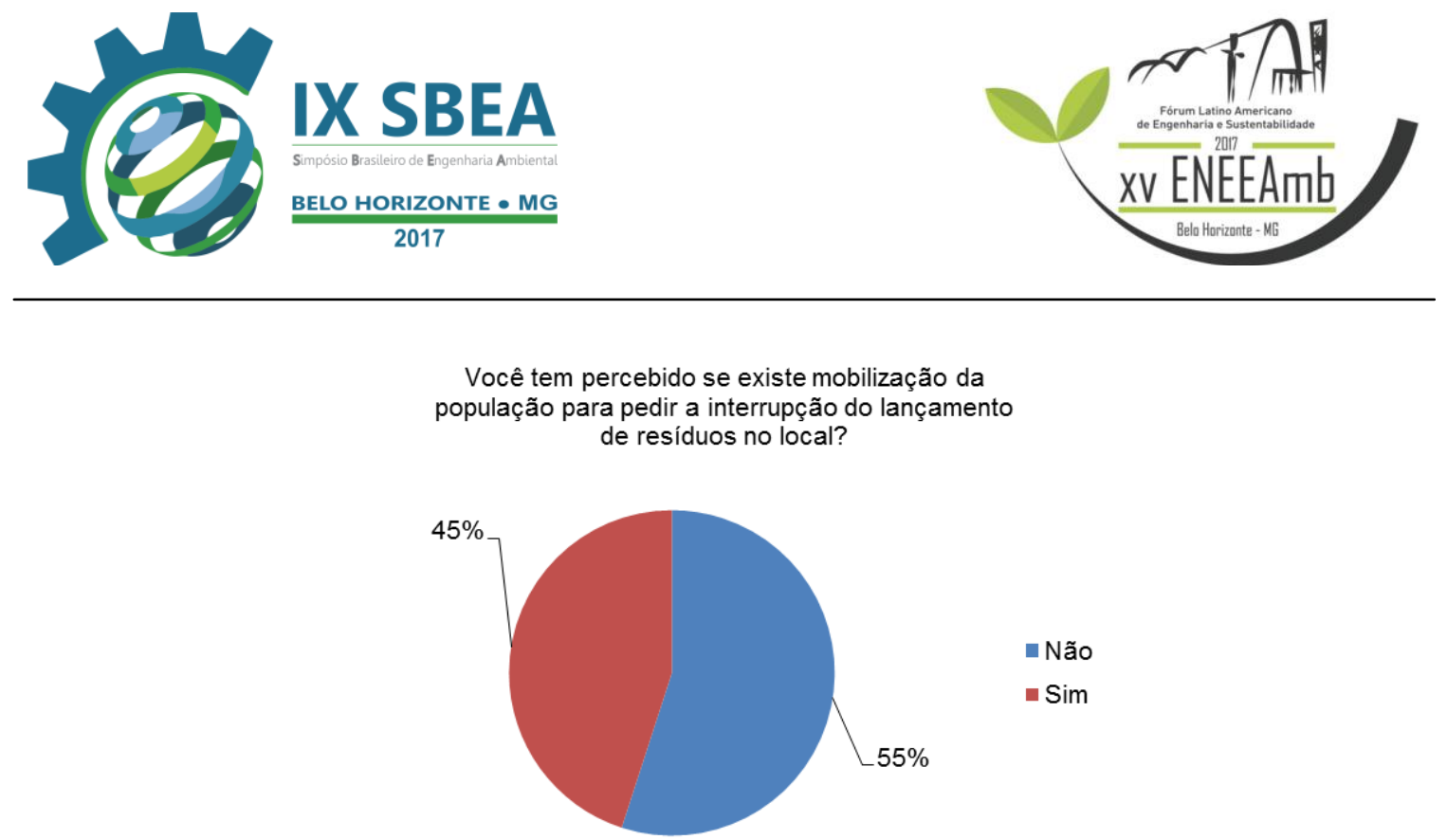

Figura 8: Percentual de respostas referentes à Questão 4.

Por fim, a última pergunta visou entender quais impactos têm sido expostos à população atualmente, tendo em vista o descarte de resíduos, ainda persistente no aterro sanitário. As respostas são mostradas na Tabela 2.

Tabela 2

Impactos desencadeados atualmente na área adjacente ao aterro sanitário.

\begin{tabular}{|l|c|}
\hline \multicolumn{1}{|c|}{ Impacto apontado } & Quantidade de moradores citando o impacto \\
\hline Presença de animais e doenças & 10 \\
decorrentes da atividade & 7 \\
\hline Mau cheiro e material particulado & 4 \\
\hline Poluição sonora & 4 \\
\hline Presença de estranhos no local & 1 \\
\hline Danos físicos às residências & 8 \\
\hline Não souberam/não quiseram responder & \\
\hline
\end{tabular}

Após análise dos resultados e diagnóstico visual da área é imprescindível que a primeira tomada de ação a ser realizada, seja o cercamento externo da área, restringindo, assim, o acesso de pessoas e animais, além de contribuir para interrupção do lançamento 


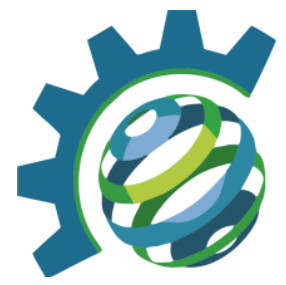

inadequado de resíduos no local. Os RCC dispostos, podem ser destinados para a reciclagem, em usina de beneficiamento a ser implantada no local.

Os resíduos provenientes de capina e poda de árvores, tem potencial para compostagem, atividade que já esteve em funcionamento no local, podendo ser reativada, visando ao recebimento dos resíduos orgânicos gerados no município, promovendo a diminuição de material destinado para aterramento. Aos demais resíduos, propõe-se a triagem, visto que muitos resíduos que são descartados em lixões ou dispostos em aterros, poderiam estar sendo utilizados de maneira a otimizar o reaproveitamento ou reciclagem dos mesmos. (NETA, 2011).

Em seguida, deve ser aplicada a técnica de remoção e realocação dos resíduos restantes para um aterro sanitário, considerando o estudo de Lanza et al. (2010). Concluída esta etapa, aconselha-se empregar técnicas de bioengenharia, utilizando materiais que visam à proteção do solo contra erosão e que reduzem os efeitos das chuvas sobre o solo, bem como a retenção de sedimentos, conforme o estudo de Magalhães (2005), assim como o controle da drenagem de chorume e funcionamento pleno das lagoas de estabilização, evitando a contaminação da água. Deve-se avaliar ainda a eficiência dos queimadores de gases, adequando-os caso seja necessário, ou até mesmo, instalando-se uma usina de aproveitamento energético, a qual poderia promover benefícios para a população dos arredores do local.

Em relação aos catadores presentes no local, estes poderão ser alocados em novas formas de trabalho, através das usinas de compostagem, de reciclagem de RCC e de aproveitamento energético, além do incentivo à formação de associações de reciclagem e cursos voltados para a educação ambiental. Estas alternativas poderiam promover emprego para a população local.

\section{CONCLUSÕES/RECOMENDAÇÕES}

O estudo realizado possibilitou dimensionar os impactos causados pela gestão inadequada de resíduos sólidos, envolvendo principalmente os resíduos sólidos urbanos, os resíduos da construção civil e os orgânicos. Sabe-se que o aterro sanitário é uma forma adequada da disposição de resíduos no solo, contudo, é imprescindível que sua 
gestão seja efetuada de forma correta, caso contrário, poderão ser desencadeados diversos fatores negativos, como os mostrados neste estudo.

A aplicação das propostas de adequação fundamentadas neste trabalho é de fundamental importância, para a área estudada, visando à sua regularização, principalmente com o meio ambiente e o meio social envolvidos. Em continuidade a este trabalho, pretende-se apresentar o estudo à Prefeitura Municipal de Betim, como uma contribuição para a gestão do empreendimento em questão, estimulando a implantação de usina de compostagem e de recuperação energética na área, bem como indicar as medidas socioambientais propostas, possibilitando o uso futuro da área e bem-estar da população local.

\section{REFERÊNCIAS BIBLIOGRÁFICAS}

ALBERTE, E. P. V.; CARNEIRO, A. P.; KAN, L. Recuperação de áreas degradadas por disposição de resíduos sólidos urbanos. Diálogos \& Ciência: Revista Eletrônica da Faculdade de Tecnologia e Ciências de Feira de Santana, Feira de Santana, v. 1, n. 5, jun. 2005 .

ASSOCIAÇÃO BRASILEIRA DE EMPRESAS DE LIMPEZA PÚBLICA E RESÍDUOS ESPECIAIS - ABRELPE. Panorama dos Resíduos Sólidos no Brasil. São Paulo: 2014. Disponível em: http://www.abrelpe.org.br/Panorama/panorama2014.pdf> Acesso em 27 mar. 2016;

ASSOCIAÇÃO BRASILEIRA DE NORMAS TÉCNICAS - ABNT. NBR 8419: Apresentação de projetos de aterros sanitários de resíduos sólidos urbanos: procedimento. Rio de Janeiro, 1992.

ASSOCIAÇÃO BRASILEIRA DE NORMAS TÉCNICAS - ABNT. NBR 15849: Aterros sanitários de pequeno porte - Diretrizes para localização, projeto, implantação, operação e encerramento. Rio de Janeiro, 2010.

BELI, E. et al. Recuperação da área degradada pelo lixão Areia Branca de Espírito Santo do Pinhal - SP. Revista Engenharia Ambiental: Pesquisa e Tecnologia, Espírito Santo do Pinhal, v. 2, n. 1, p.135-148, dez. 2005.

BRAGA, B. et al. Introdução à Engenharia Ambiental: $\mathrm{O}$ desafio do desenvolvimento sustentável. 2. ed. São Paulo: Pearson/Prentice Hall, 2005. 318 p. 


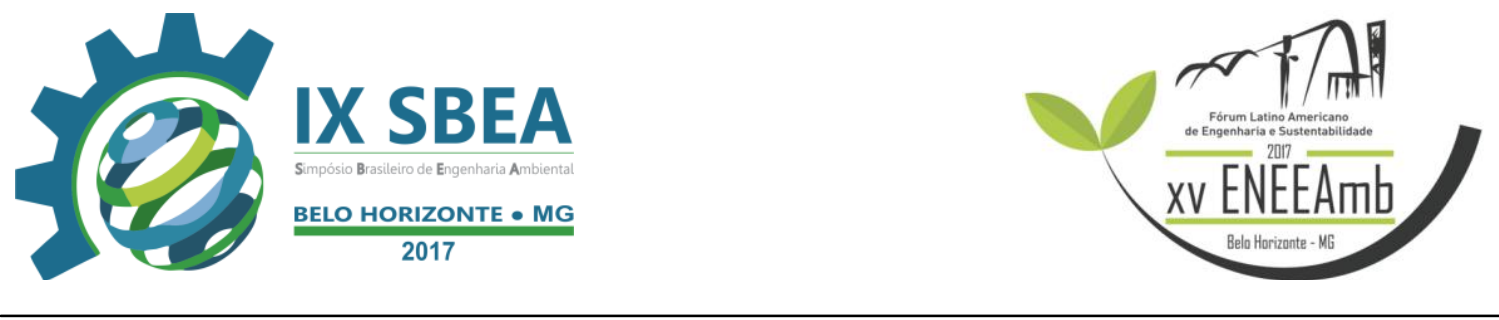

BRASIL. Lei $\mathbf{n}^{\mathbf{1}}$ 12.305, de 02 de agosto de 2010. Institui a Política Nacional de Resíduos Sólidos; altera a Lei no 9.605, de 12 de fevereiro de 1998; e dá outras providências. Brasília, 2010.

CAVAlCANTE, S.; FRANCO, M. F. A. Profissão perigo: percepção de risco à saúde entre os catadores do lixão do Jangurussu. Revista Mal-Estar Subj., Fortaleza, v. 7, n. 1, p. 211-231, mar. 2007

GOUVEIA, N. Resíduos sólidos urbanos: impactos socioambientais e perspectiva de manejo sustentável com inclusão social. Revista Ciência \& Saúde Coletiva, Rio de Janeiro, v. 17, n. 6, p.1503-1510, jun. 2012.

INSTITUTO BRASILEIRO DE GEOGRAFIA E ESTATÍSTICA - IBGE. Cidades.

Betim, $2016 . \quad$ Disponível em
<http://cidades.ibge.gov.br/xtras/perfil.php?codmun=31067 0/> Acesso em 13 mar. 2016;

LANZA, V. C. V. et al. Caderno técnico de reabilitação de áreas degradadas por resíduos sólidos urbanos. Programa Minas sem lixões. Belo Horizonte: Fundação Estadual do Meio Ambiente / Fundação Israel Pinheiro, 2010. 36 p. Disponível em: $<$ http://www.feam.br/images/stories/Flavia/areas_de gradadas.pdf> Acesso em 29 mai. 2016;

MAGAlHÃES, A. F. Avaliação do desempenho de técnicas de bioengenharia na proteção e conservação da cobertura final de taludes em aterros de disposição de resíduos sólidos urbanos: estudo de caso para o aterro sanitário de Belo Horizonte, MG. 2005. 169 f. Dissertação (Mestrado) - Curso de Saneamento, Meio Ambiente e Recursos Hídricos, Departamento de Engenharia Sanitária e Ambiental, Universidade Federal de Minas Gerais, Belo Horizonte, 2005. Disponível em: <http://www.smarh.eng.ufmg.br/defesas/150M.PDF>. Acesso em: 12 jun. 2016.

MUCELIN, C. A.; BELLINI, M. Lixo e impactos ambientais perceptíveis no ecossistema urbano. Revista Sociedade \& Natureza, Uberlândia, v. 20, n. 1, p.111124, jun. 2008.

RESENDE, L. A. et al. Crescimento e sobrevivência de espécies arbóreas em diferentes modelos de plantio na recuperação de área degradada por disposição de resíduos sólidos urbanos. Revista Árvore, Viçosa, v. 39, n. 1, p.147-157, fev. 2015. 